\title{
ESTUDO APLICADO DE DEA PARA AVALIAÇÃO DA EFICIÊNCIA DOS AEROPORTOS DA INFRAERO
}

DOI 10.37619/issn2447-5378.v7i1.328.40-49

\author{
A.A. Silva ${ }^{1, *} ;$ L.E. Andrade ${ }^{1} ;$ M.V. Nascimento ${ }^{1}$ \\ 1 Faculdade de Tecnologia de São José dos Campos - Professor Jessen Vidal \\ Av. Cesare Mansueto Giulio Lattes, 1350 - Eugênio de Melo, São José dos Campos/SP, \\ CEP.: 12247-014, Brasil. Telefone: (12) 3905-2423 \\ *adenilson.silva2@fatec.sp.gov.br
}

\begin{abstract}
RESUMO: O Brasil é um país de dimensões continentais com uma extensa rede de aeroportos distribuída em todo o seu território. O presente trabalho tem como objetivo avaliar a eficiência dos aeroportos administrados pela INFRAERO, localizados em várias regiões do país, utilizando a técnica Análise por Envoltória de Dados (DEA). Para realizar essa avaliação, foram coletados dados referentes ao ano de 2019 de 44 aeroportos administrados pela INFRAERO. As variáveis empregadas nessa avaliação foram três inputs e dois outputs. Em seguida, utilizou-se o método DEA - BCC orientado para o output para identificar quais melhorias são necessárias para os aeroportos ineficientes, de maneira a incrementar o nível operacional. Os resultados apontaram que dos 44 aeroportos em estudo, apenas 4 se mostraram eficientes, são eles, os Aeroportos de Congonhas, Santos Dumont, Bacacheri-Curitiba e Aeroporto de Jacarepaguá. O Aeroporto de Bagé/RS foi o local com menos destaque, obtendo eficiência relativa de $1 \%$.
\end{abstract}

PALAVRAS-CHAVE: Análise de envoltória de Dados, Eficiência, Aeroportos.

ABSTRACT: Brazil is a country of continental dimensions with an extensive network of airports distributed throughout its territory. The present work aims to evaluate the efficiency of airports managed by INFRAERO, located in various regions of the country, using the Data Envelopment Analysis (DEA) technique. To carry out this assessment, data for the year 2019 were collected from 44 airports managed by INFRAERO. The variables used in this evaluation were three inputsand two outputs. Then, the output-oriented DEA - BCC method was used to identify which improvements are needed for inefficient airports in order to increase the operational level. The results showed that out of the 44 airports under study, only 4 proved to be efficient, namely Congonhas Airport, Santos Dumont, Bacacheri-Curitiba and Jacarepaguá Airport. Bagé Airport / RS was the place with the least prominence, obtaining relative efficiency of $1 \%$.

Keywords: Data Envelopment Analysis, Efficiency, Airports.

\section{INTRODUÇÃO}

O transporte aéreo é essencial para o país, proporcionando acessibilidade e mobilidade de pessoas e de mercadorias de diversos setores econômicos. Esse modal de transporte promove a integração do território nacional e se constitui em um setor estratégico para o desenvolvimento do país (IPEA, 2010).

No cenário nacional, a aviação regular tem uma importância fundamental para a promoção do turismo, transporte de pessoas e distribuição de cargas, (MCKINSEY \& COMPANY, 2010).

Visto a relevância do setor aéreo para o país, faz-se necessário a aplicação de estudos que avaliem a eficiência da movimentação de passageiros nos aeroportos. Tal conjectura é fundamental 
para o aprendizado e pode vir a contribuir para inserir os aeroportos brasileiros com competitividade internacional, identificando as características de infraestrutura de cada um, permitindo que façam correções de suas deficiências e, assim, busquem saná-las, garantindo qualidade para atender a demanda.

O presente trabalho se propõe a mensurar a eficiência dos aeroportos brasileiros administrados pela estatal Empresa Brasileira de Infraestrutura Aeroportuária- INFRAERO, dada à capacidade de infraestrutura instalada, tendo objetivo específico a coleta de dados disponibilizados por órgãos governamentais referentes à análise das características físicas como as pistas de pouso, pistas de táxi, pátio de estacionamento de aeronave e terminal de passageiros.

Para cumprir o objetivo, será aplicada a metodologia da Análise de Envoltória de Dados (Data Envelopment Analysis - DEA) para aferir a eficiência dos aeroportos através dos dados coletados.

\section{EMBASAMENTO TEÓRICO}

Para a realização deste trabalho, o levantamento bibliográfico de embasamento teórico foi realizado por meios digitais de informação, buscando livros, dissertações, teses, trabalhos publicados e outras publicações técnicas que permitem a melhor compreensão dos conceitos básicos discutidos neste trabalho. Como princípio, foram estudados trabalhos que caracterizam o planejamento aeroportuário e suas vertentes. Conforme Severino, (2007 p. 122) "a pesquisa bibliográfica é aquela que se realizam a partir do registro disponível, decorrente de pesquisas anteriores, em documentos impressos, como livros, artigos, teses, etc.”.

\subsection{Planejamento Aeroportuário}

Conforme explica Ashford e Wright (1992)o aeroporto é um dos mais importantes elementos da infraestrutura de transporte de uma região, e representa uma parte essencial do sistema de transporte aéreo, pois é o local físico onde ocorre a troca do modal terrestre pelo modal aéreo e vice versa. Portanto, os aeroportos são ferramentas adicionais de desenvolvimento social, econômico, e até cultural, para as cidades atendidas, para o país e também para o fenômeno do turismo. Kawamoto (1994) ressalta o papel do transporte no desenvolvimento social e econômico e defende que o planejamento aeroportuário só terá sucesso se ele estiver integrado ao planejamento social e econômico da nação ou da região. Os aeroportos são os equipamentos urbanos que permitem o acesso rápido e direto aos principais centros econômicos do país e também promove um intercâmbio inter-regional eficiente, dadas as grandes distâncias entre os centros econômicos regionais Com isto, a administração desses complexos deve ser encarada com extrema importância e zelo para garantir o sucesso de todo processo socioeconômico envolvido. Nessa perspectiva, o fornecimento de um bem público requer sempre a atuação estatal, seja através da exploração direta, seja através da definição de regulamentos para disciplinar a exploração por agentes privados (ANNUATI, 2001).

O governo federal foi o responsável pela exploração dos principais aeroportos nacionais através da estatal Empresa Brasileira de Infraestrutura Aeroportuária-INFRAERO. A década iniciada em 2010 marcou o processo de concessão à iniciativa privada dos principais aeroportos brasileiros. No entanto, a rede INFREAERO possui um conjunto de 44 aeroportos sob sua administração, sendo o Aeroporto de Congonhas em São Paulo, o mais influente. Em 2019, a rede INFRAERO contabilizou 1.2 milhões de pousos e decolagens de aeronaves nacionais e estrangeiras, transportando 85 milhões de passageiros em seus aeroportos. (INFRAERO, 2019).

Conforme explica Linhares (2012), outros agentes responsáveis pelo planejamento e uso das estruturas aeroportuárias no Brasil são Governos de Estado, Prefeituras Municipais e em alguns casos específicos fica a cargo de empresas privadas que mantém contratos com as entidades da federação. 


\section{Congress of Industrial Management and Aeronautical

\subsection{Infraestrutura Aeroportuária}

A infraestrutura clamava por melhorias no momento em que a indústria aeronáutica se tornava cada vez mais fortes, eram eminentes a transigência e a modernização aeroportuária. Assim foi idealizada a INFRAERO, mediante proposição do tenente brigadeiro do ar Joelmir Campos de Araripe Macedo, de 14.11.72, consubstanciada na Exposição de Motivos número 364, de 16.11.72, enviada ao Congresso Nacional pelo presidente da República Emílio Garrastazu Médici, resultando na Lei número 5.862, de 123.11.72, que autorizou a sua criação. Assim, em 31 de maio de 1973, a INFRAERO iniciava sua missão na gestão de aeroportos.

A INFRAERO foi constituída com as seguintes finalidades: implantar, administrar, operar e explorar industrial e comercialmente a infraestrutura aeroportuária e de apoio à navegação aérea e prestar assessoramento e consultoria na construção de aeroportos e nas áreas em que atua (INFRAERO, 2018). Em 12 de abril de 2000 a INFRAERO se desvinculou do Ministério da Aeronáutica e passou para a esfera do Ministério da Defesa.

A reestruturação da aviação civil viveu outro capítulo importante, em 27 de setembro de 2005, pela lei 11.182, foi criada a Agência Nacional de Aviação Civil (ANAC), vinculada ao Ministério da Defesa e que substituiu o Departamento de Aviação Civil - DAC. A ANAC é uma autarquia especial, com independência administrativa, personalidade jurídica própria, patrimônio e receitas próprias para executar atividades típicas da Administração Pública, que requerem para seu melhor funcionamento, com gestão administrativa e financeira descentralizada. (ANAC, 2019). Entre outras atribuições, a ANAC é o órgão responsável por outorgar concessões de serviços aéreos e de infraestrutura aeronáutica e aeroportuária, regular as concessões, estabelecer regime tarifário para exploração da infraestrutura aeroportuária, regular as atividades de administração e exploração de aeródromos, inclusive as exercidas pela INFRAERO.

Segundo Ballou (2009) historicamente a infraestrutura de transporte tem determinado o desenvolvimento urbano e a localização dos negócios. No século 21, os aeroportos desempenharam este papel que já foi dos mares, rios, ferrovias e estradas.

Conforme explica Barbosa (2014) não há crescimento econômico sustentável sem a existência da infraestrutura eficiente e eficaz, que atenda aos objetivos diversos de uma nação: viabilizando o produto potencial, integrando a população à economia nacional, por meio de modais de transportes e sistemas de comunicações eficientes que interliguem, de fato, as regiões do país e minimizem os desperdícios de recursos ao otimizar sua utilização.

Conforme disposto no Código Brasileiro de Aviação (CBA, 1986), o sistema aeroportuário é constituído pelo conjunto de aeródromos brasileiros, com as pistas de pouso, pistas de táxi, pátio de estacionamento de aeronave, terminal de carga aérea, terminal de passageiros e os respectivos serviços. Excluindo-se os serviços, os demais itens listados constituem a infraestrutura aeroportuária. O "Lado Ar" refere-se a instalações aeroportuárias associadas com movimento de aeronaves, utilizadas principalmente para pouso e decolagem. Alguns dos principais componentes do "Lado Ar" são: Pista de Pouso e Decolagem, Pista de Táxi de Saída Rápida. O "Lado Terra" refere-se às estruturas de processamento de passageiros e de processamento e armazenamento de carga, além dos pátios de manobra e estacionamento de aeronaves.

\subsection{Análise de Envoltória de Dados (DEA)}

A busca pela excelência passa necessariamente pela avaliação do desempenho organizacional. DEA é um método não paramétrico projetado para medir o desempenho de uma empresa, organização, programa, etc.; ou seja, tudo o que é produzido por uma unidade de tomada de decisão (DMU). Essa metodologia, proposta inicialmente por Charnes, Cooper e Rhodes (1978) se presta a 


\section{ISSN $2447-5378$}

uma abordagem multicritério adequada para avaliação de desempenho, que considera uma variedade de entradas e saídas. A abordagem DEA possibilita definir objetivos direcionados à minimização de insumos; isto é, utilizar a menor quantidade de recursos para obter um determinado resultado ou para maximizar a produção; isso é para obter o melhor resultado com a aplicação de um determinado nível de recursos.

A Análise de Envoltória de Dados (Data Envelopment Analysis) tem fundamentação da matemática para a análise e medição de eficiência de certa dependência produtiva. Conforme explica Gomes (2001 apud SOARES DE MELO; GOMES, 2004), seu uso, é de particular interesse quando se deseja determinar a eficiência de unidades produtivas onde não seja relevante ou não se deseja considerar somente o aspecto financeiro. Primeiro deve-se selecionar as unidades produtivas, chamadas DMU's. Posteriormente, descreve-se o processo produtivo das unidades analisadas no caso os 44 aeroportos administrados pela INFRAERO.

De posse desses dados coletados executa-se o método, utilizando os softwares disponíveis. Como exemplo cita-se o software EMS (Efficiency Measurement System), que realiza o cálculo de eficiência através de dados digitados em planilha do MS-Excel.

Normalmente a eficiência é medida por um conjunto pré-determinado de entradas e saídas (COOK; BALA, 2007). O conjunto de DMU's deve ser homogêneo tendo em comum a utilização do mesmo recurso de entrada (inputs) e a produção das mesmas saídas (outputs). Em geral o método é utilizado para o input ou para o output dependendo se o objetivo é a redução de recursos ou no aumento da produção (LINS, et al. 2007).

Com a utilização do método de análise DEA, a projeção das unidades ineficientes é delimitada por um conjunto de referência de unidades eficientes. Conforme explica Peña (2008) as unidades selecionadas devem ser semelhantes, isto é, devem produzir os mesmos bens e serviços, utilizando os mesmos insumos. Quanto ao número de unidades, não existem normas definidas, porém, quanto maior for a quantidade de unidades analisadas, maior será a capacidade discriminatória do modelo.

A Análise por Envoltória de Dados (DEA) é uma técnica baseada em programação linear, com o objetivo de medir o desempenho de unidades operacionais ou tomadoras de decisão (Decision Making Units - DMU), quando a presença de múltiplas entradas e múltiplas saídas torna difícil realizar uma comparação (LINS; MEZA, 2000).

O objetivo da técnica DEA é construir um conjunto de referências, permitindo a classificação das DMUs em unidades eficientes ou ineficientes, tendo como referencial a superfície formada por esse conjunto (SOARES DE MELLO et al., 2005). As unidades eficientes são localizadas sobre a fronteira enquanto as ineficientes localizam-se abaixo.

Assim, chegamos à eficiência de cada DMU. De posse desses valores, podemos calcular o quanto as DMUs menos eficientes deveriam melhorar, traçando uma meta de redução de inputs ou aumento de outputs, dependendo do modelo de orientação escolhido.

O modelo BCC (Banker, Charnes e Cooper, 1984), ou também conhecido como O VRS (Varieble Return Scale), originou do método DEA e se incorporou ao mesmo, com a finalidade trabalhar com qualquer variação nos insumos gerando uma alternância proporcional nos produtos. Estabelece-se a eficiência ocorrendo na razão de soma ponderada dos outputs e a soma ponderada dos inputs. Como um aeroporto já possui infraestrutura pré-instalada, optou-se pelo modelo BCC orientado a output para esse trabalho. Nesse caso, estruturou-se um método para avaliar se os aeroportos em análise conseguem obter maiores índices de eficiência dada a relação de outputs e inputs.

\section{DESENVOLVIMENTO DA TEMÁTICA}


A pesquisa apresenta uma abordagem quantitativa com objetivo de explorar 44 (quarenta e quatro) aeroportos brasileiros administrados pela INFRAERO, sendo esses aeroportos internacionais ou regionais, através de dados coletados e disponibilizados pela INFRAEREO referente ao ano de 2019. Inicialmente, para a realização do método dos multicritérios, segundo Gomes (2001 apud Soares de Mello, 2004), foram selecionados três inputs: (1) pista de pouso/decolagem com seu comprimento em metros, (2) capacidade dos terminais aeroportuários em $\mathrm{M}^{2} \mathrm{e}$ (3) número de posições de estacionamento para os aviões e dois outputs como: (1) a movimentação de aeronaves e (2) a movimentação de passageiros embarcados e desembarcados.

A partir dessa seleção, foi necessário definir quais variáveis estavam correlacionadas entre si e o que será detalhado na próxima seção. Para analisar os aeroportos, utilizou-se os dados dos inputs e outputs referentes ao ano de 2019, e com os 44 aeroportos selecionados: Aeroporto Internacional de Belém, Aeroporto de Bagé, Aeroporto de Belo Horizonte/Pampulha, Aeroporto de Curitiba (Bacacheri), Aeroporto Boa Vista, Aeroporto Campo Grande, Aeroporto Parauapebas, Aeroporto Corumbá, Aeroporto Afonso Pena, Aeroporto Cruzeiro do Sul, Aeroporto de Manaus, Aeroporto de Foz do Iguaçu, Aeroporto de Goiânia, Aeroporto de Altamira, Aeroporto de Imperatriz, Aeroporto de Belém (Brigadeiro), Aeroporto de Jacarepaguá, Aeroporto Joinville, Aeroporto de Londrina, Aeroporto de Montes Claros, Aeroporto de Macapá, Aeroporto Campo de Marte, Aeroporto de Navegantes, Aeroporto de Parnaíba, Aeroporto de Palmas, Aeroporto de Pelotas, Aeroporto de Petrolina, Aeroporto de Ponta Porã, Aeroporto Belo Horizonte Carlos Prates, Aeroporto de Porto Velho, Aeroporto de Rio Branco, Aeroporto Santos Dumont, Aeroporto de São José Dos Campos, Aeroporto de São Luís, Aeroporto de Santarém, Aeroporto de Teresina, Aeroporto de Tefé, Aeroporto de Tabatinga, Aeroporto Paulo Afonso, Aeroporto Uruguaiana, Aeroporto Uberlândia e Aeroporto Uberaba, Aeroporto de Marabá e Aeroporto de Congonhas.

Considerando que a infraestrutura dos aeroportos são variáveis fixas, devido sua estrutura montada e sua capacidade restrita de investimentos, e os outputs podem ser variados dependendo do época do ano, decidiu-se utilizar o modelo BCC (BANKER,CHARNES, COOPER, 1984) para o output e software EMS (Efficiency Measurement System) que por sua vez realiza os cálculos de eficiência dos aeroportos através de planilhas inseridas no MS-Excel.

\section{RESULTADOS E DISCUSSÃO}

A Figura 1 ilustra os resultados de eficiência dos aeroportos, gerados pelo modelo DEA-BCC orientado ao output. Observa que dos 44 aeroportos analisados, apenas 4 obtiveram 100\% de eficiência, Aeroporto de Congonhas, Aeroporto de Jacarepaguá, Aeroporto Santos Dumont e Aeroporto Bacacheri-Curitiba.

Figura 1. Resultados de eficiência dos aeroportos em estudo. 


\section{Congress of Industrial} Management and Aeronautical Technology

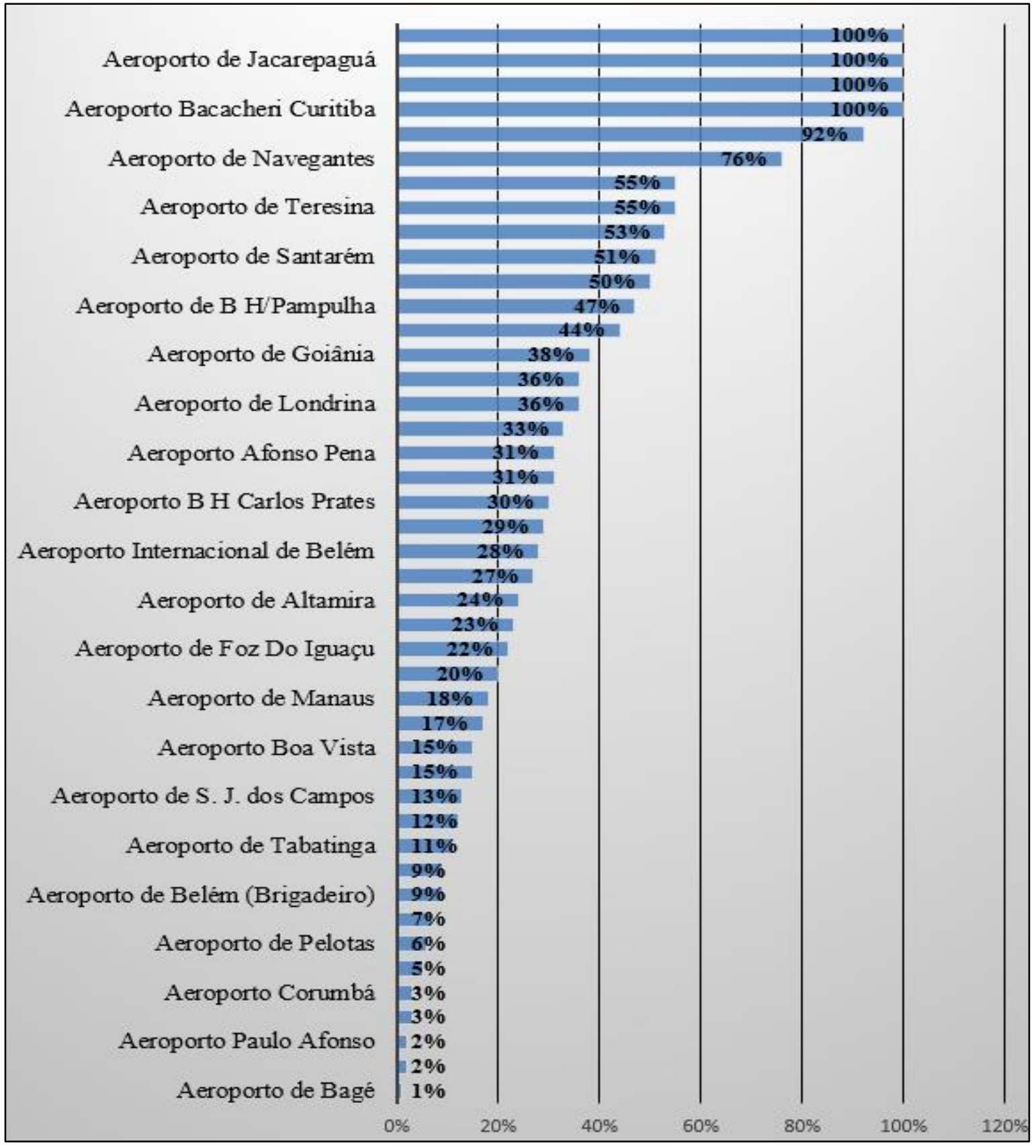

Fonte: Elaborado pelos Autores (2020)

Nesta análise foi aplicada como inputs, o tamanho da pista principal e o tamanho total dos terminais de passageiros. Como outputs foram aplicados a movimentação de passageiros (embarque e desembarque) e a movimentação de aeronaves (pouso e decolagens) relativos ao ano de 2019. Como exemplos, cita se os dados do Aeroporto de Congonhas utilizados na parametrização do sistema: inputs, 1940 metros de comprimento da pista e $64579 \mathrm{~m}^{2}$ de área do terminal de passageiros, os outputs são 217254 pousos e decolagens no Ano 2019 e 22681392 passageiros embarcados e desembarcados no ano 2019 e cita se também os dados do Aeroporto de Bagé utilizados na parametrização do sistema: inputs, 1500 metros de comprimento da pista e $600 \mathrm{~m}^{2}$ de área do terminal de passageiros, os outputs são 527 pousos e decolagens no Ano 2019 e 1950 passageiros embarcados e desembarcados no ano 2019. 
Como demonstrado na Figura 1 os aeroportos com baixa eficiência precisam melhorar o seu desempenho. O sentido do modelo BCC orientado a output indica que os aeroportos com baixa eficiência, deveriam aumentar os seus níveis de output para se tornarem eficientes, ou seja, aumentar a movimentação de aeronaves e consequentemente a movimentação de passageiros.

A Figura 2 ilustra, em quantas vezes os aeroportos ineficientes precisariam aumentar os seus outputs, ou seja, em quantas vezes teriam que aumentar a movimentação de aeronaves e a movimentação de passageiros, para se tornarem eficientes.

Figura 2. Aumento necessário de outputs (Saídas)

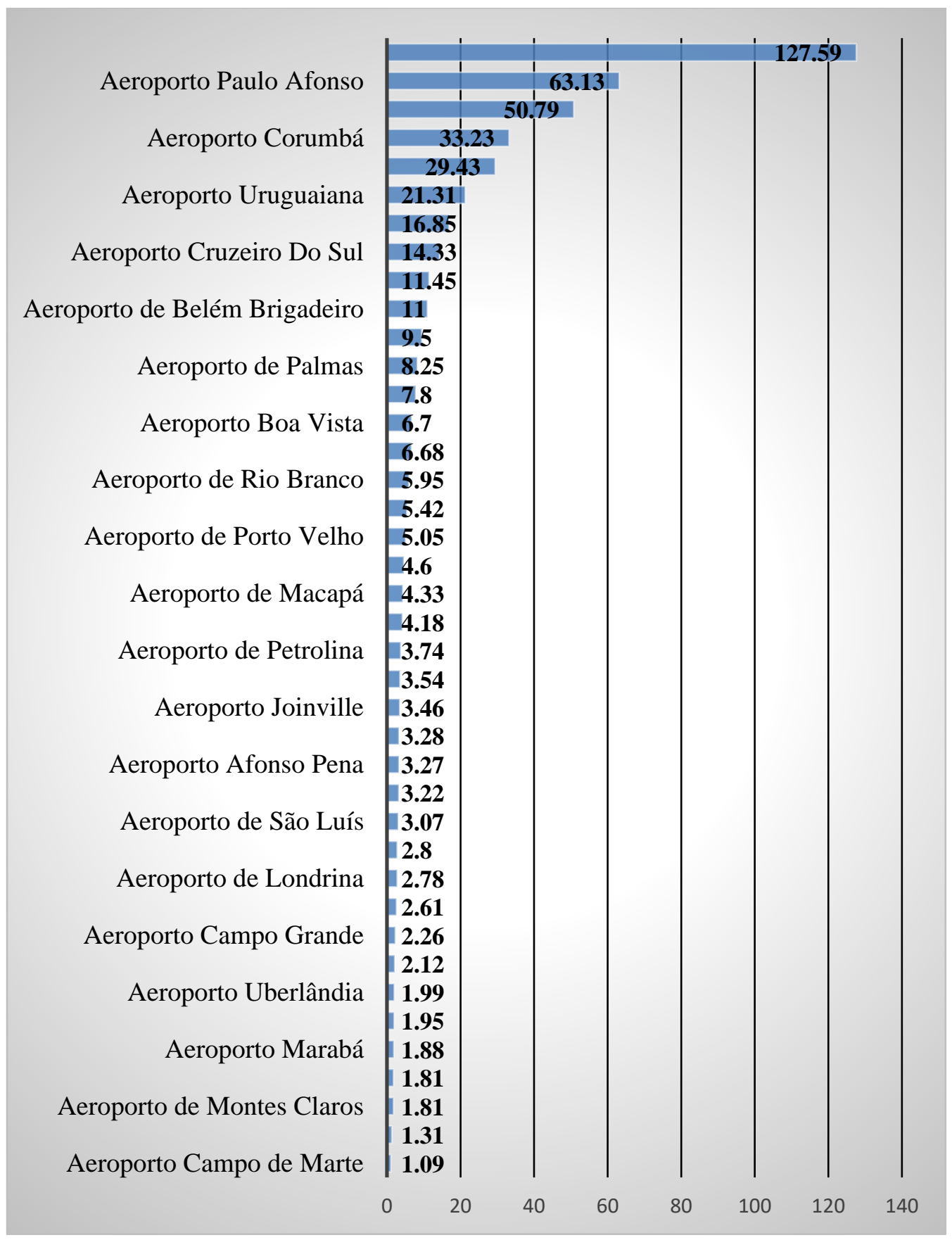

Fonte: Elaborado pelos Autores (2020) 
Como por exemplo, cita-se o Aeroporto de Bagé, que movimentou no ano de 2019, 1950 passageiros, dados obtidos pela INFRAERO, ele poderia estar produzindo 127,59 vezes a mais do que seus resultados atuais, ou seja, para se tornar eficiente, teria que movimentar 248800 passageiros. Conforme dados os valores necessários de aumento são resultantes do modelo de programação linear desenvolvido. Esse valor indica o potencial do aeroporto dada a infraestrutura instalada (inputs).

Os Aeroportos de Congonhas e Santos Dumont que obtiveram 100\% de eficiência são os aeroportos que mantém a existência da estatal, porém, são cotados para serem cedidos à iniciativa privada. O Aeroporto de Bacacheri é o único dos nove aeroportos incluídos no Bloco Sul da 6 a rodada de concessões de aeroportos que atende exclusivamente a aviação geral, ou seja, não recebe voos regulares de passageiros. De acordo com dados da Infraero, o Aeroporto de Bacacheri é um aeroporto lucrativo, apesar de não receber a aviação comercial. Entre os aeroportos da Rede Infraero, Jacarepaguá é o quarto em movimentação de aeronaves, de acordo com dados de 2019. Ele fica atrás apenas de Congonhas, que lidera a lista; seguido por Santos Dumont e Curitiba. O diferencial é que Jacarepaguá recebe apenas aviação geral e executiva, com destaque para a operação off-shore; sendo que os outros terminais contam com operações comerciais de maior porte.

A ANAC aprovou o edital do leilão da sexta rodada de concessões, que vai licitar 22 aeroportos divididos em três blocos regionais.

- $\quad$ Bloco Sul: Curitiba, Foz do Iguaçu (PR), Navegantes (SC), Londrina (PR), Joinville (SC), Bacacheri (PR), Pelotas (RS), Uruguaiana (RS) e Bagé (RS);

- $\quad$ Bloco Central: Goiânia, São Luís, Teresina, Palmas, Petrolina (PE) e Imperatriz (MA);

- Bloco Norte: Manaus, Porto Velho, Rio Branco, Cruzeiro do Sul (AC), Tabatinga (AM), Tefé (AM) e Boa Vista.

Segundo a ANAC, juntos os terminais responderam por $11 \%$ dos passageiros que voaram no Brasil em 2019, foram 23,9 milhões de embarques e desembarques nesses aeroportos.

\section{CONSIDERAÇÕES FINAIS}

O principal objetivo deste trabalho foi avaliar a infraestrutura aeroportuária por meio do desenvolvimento de um modelo DEA. A aplicação do modelo permitiu gerar uma estimativa de valor para eficiência de 44 (quarenta e quatro) aeroportos brasileiros, todos administrados pela INFRAERO. A elaboração do modelo procedeu uma pesquisa de coleta de dados referentes aos aspectos técnicos de cada aeroporto, relativo ao ano de 2019.

Expondo as características físicas dos aeroportos como pista de pouso/decolagem, capacidade dos terminais aeroportuários e número de posições de estacionamento para os aviões, foi realizada a avaliação das movimentações de aeronaves e de passageiros. Com isso, o modelo matemático gerado permitiu medir a eficiência desses aeroportos dada a sua produtividade (relação de resultado gerado dado a infraestrutura instalada). Com base nestes resultados obtidos, foi possível identificar quais aeroportos necessitam melhorar o seu desempenho. Para isso, a maioria deles precisam alocar mais recursos nas suas áreas de infraestruturas, de maneira a melhorar a eficiência técnica e aumentar a escala de produção, ou seja, aumentar a movimentação de aeronaves e consequentemente, aumentar a movimentação de passageiros. O modelo DEA indicou que 33 aeroportos não atingem $50 \%$ do que seriam capazes de movimentar anualmente.

$\mathrm{O}$ aeroporto de Bagé RS foi o local com menos destaque, obtendo eficiência relativa de $1 \%$, e terá que aumentar em 127,59 vezes sua movimentação de passageiros para se tornar eficiente. A Infraero segue realizando melhorias no terminal, para a certificação junto à Agência Nacional de Aviação Civil (ANAC), para que o aeroporto, receba aeronaves com capacidade superior a 30 passageiros. 
Este estudo esteve limitado ao vínculo das infraestruturas e ao que elas movimentam. Como destacado nessa argumentação, é importante ressaltar que novas pesquisas devem ser realizadas para comprovar os fatos argumentados na pesquisa. Em termos de recomendações para trabalhos futuros, sugere-se que os dados aqui analisados sejam utilizados em modelos matemáticos diferentes dos empregados, podendo alterar variáveis. Um exemplo é a inserção de variáveis relacionadas às receitas operacionais obtidas pelos aeroportos.

\section{REFERÊNCIAS}

ANAC. Relatório de Atividades 2019 Disponível em https://www.anac.gov.br/publicacoes/publicacoesarquivos/Relatorio_de_Atividades_2019._pdf acesso em 20 de julho de 2020.

ANNUATI N. F. Regulamentação dos Mercados. In: Manual de Economia. São Paulo 3.ed., Saraiva, 2001.

ASHFORD, N.; WRIGHT, P. H. Airport Engineering. John Willey \&Sons. New York, $3^{\text {a }}$ ed., 1992.

BALLOU, R. H. Logística Empresarial: transportes, administração de materiais e distribuição física. 1. ed. São Paulo: Atlas, 2009.

BANKER, R. D.; CHARNES, A.; COOPER, W.W. Some models for estimating technical and scale inefficiencies in data envelopment analysis. Management science, v. 30, n. 9, p. 1078-1092, 1984.

BARBOZA, M. A. M. A ineficiência da infraestrutura logística do Brasil. Revista Portuária, 2014.

CHARNES, A.; COOPER, W. W.; RHODES, E. Measuring the efficiency of decision making units. European journal of operational research, v. 2, n. 6, p. 429-444, 1978.

CÓDIGO BRASILEIRO DE AVIAÇÃO. Disponível em: http://www.planalto.gov.br/ccivil_03/leis/17565.htm - CBA - Código Brasileiro de Aviação - 1986. Acesso em: 30 de maio de 2020

COOK, W. D.; BALA, K. Performance measurement and classification data in D. E.A: Input-oriented model. Omega, v. 35, n. 1, p. 39-52, 2007.

Empresa Brasileira de Infraestrutura Aeroportuária INFRAERO. Relatório Anual de 2018,Disponível em http://www4.infraero.gov.br/media/677261/relatorio_anual_2018.pdf acesso em 30 de Maio de 2020.

Empresa Brasileira de Infraestrutura Aeroportuária - INFRAERO. Relatório Anual de 2019 Disponível em https://transparencia.infraero.gov.br/wp-content/uploads/2020/09/Relat\%C3\%B3rioAnual-2019-1.pdf acesso em 30 de Maio de 2020.

Instituto de Pesquisa Econômica Aplicada. IPEA. Infraestrutura econômica no Brasil diagnósticos e $\begin{array}{llll}\text { perspectivas } & \text { para } & 2025 & \text { Disponível em }\end{array}$ 


\section{ISSN $2447-5378$}

https://www.ipea.gov.br/portal/index.php?option=com_content\&view=article\&id=6472 acesso em 25 de Maio de 2020

KAWAMOTO, E. (1994) Análise de Sistemas de Transportes. $2^{\text {a }}$ ed., revista e aumentada. Departamento de Transportes. Escola de Engenharia de São Carlos. Universidade de São Paulo. São Carlos.

LINHARES, G.C. Planejamento aeroportuário no Brasil: discussão sobre contribuições da prospectiva estratégica. J. Transp. Lit. [online]. 2012, vol.6, n.4.

LINS, M. E. et al. Análise Envoltória de Dados (DEA) para avaliação de hospitais universitários brasileiros. Ciência \& Saúde Coletiva, v.12, n.4, p. 985-998, 2007.

LINS, M. P.E.; MEZA, L. Análise Envoltória de Dados e perspectivas de integração no ambiente de Apoio à Decisão. Rio de Janeiro: Coppe/UFRJ, 2000.

MCKINSEY \& COMPANY. Estudo do setor de transporte aéreo do Brasil: relatório consolidado. BNDES 2010.2 Disponível em https://web.bndes.gov.br/bib/jspui/bitstream/1408/7666/2/Estudo\%20do\%20setor\%20de\%20transp orte\%20a\%c3\%a9reo\%20do\%20Brasil_jan.2010_final_P_BD.pdf acesso em 20 de Maio de 2020.

PEÑA, C. R. Um modelo de avaliação da eficiência da administração pública através do método análise envoltória de dados (DEA). Revista de Administração Contemporânea, v. 12, n. 1, p. 83106, 2008.

SEVERINO, A. J. Teoria e prática científica. Metodologia do trabalho científico, v. 23, pág. $122,2007$.

SOARES DE MELLO, J. C. C. B.; GOMES, E. G. Eficiências aeroportuárias: uma abordagem comparativa com análise de envoltória de dados. Revista de Economia e Administração, v. 3, n. 1, 2004.

SOARES DE MELLO, J.C.C. B; MEZA, L.A.; GOMES, E.G.; BIONI NETO, L. Curso de Análise de Envoltória de Dados. In: Anais XXXVII Simpósio Brasileiro de Pesquisa Operacional (SBPO). Gramado, RS, 2005. 